\title{
REFLEXÕES ONTOLÓGICAS E EPISTEMOLÓGICAS SOBRE O CAMPO JURÍDICO
}

\section{REFLECTIONS ONTOLOGICAL AND EPISTEMOLOGICAL ON THE LEGAL FIELD}

\section{Luis Fernando Sgarbossa ${ }^{1}$}

RESUMO: O presente artigo propõe-se a problematizar, a partir de uma interlocução interdisciplinar que privilegia os campos da Antropologia, a História e a Sociologia, o objeto e os métodos da Ciência Jurídica contemporânea, procurando resgatar o valor do pensamento de autores como Eugen Ehrlich e Julius Hermann Von Kirchmann. O artigo resgata críticas à concepção reducionista do direito baseada no positivismo, no legalismo e no estatismo, propugnando uma concepção ampla de direito, reconhecido como fenômeno humano e social multifacetário. Com base no pensamento de Paolo Grossi, propõe um resgate da visão ordenamental do direito, em lugar da concepção meramente potestativa vigente. $\mathrm{O}$ estudo apresenta uma crítica a abordagem meramente tecnológica do direito, em prol de uma redefinição metodológica que incremente a ciência jurídica, e sustenta que o afastamento de mitos como o do monismo jurídico possam contribuir para uma Ciência Jurídica do porvir que não sucumba ante o positivismo estrito, o oficialismo e o tecnicismo estrito.

Palavras-chave: Ciência do Direito. Métodos. Reducionismo.

ABSTRACT: The present article proposes to problematize, from an interdisciplinary dialog that focuses on the fields of Anthropology, History and Sociology, the object and the methods of Science contemporary Legal, looking for redeeming the value of thinking of authors such as Eugen Ehrlich and Julius Hermann Von Kirchmann. The article demonstrates the critical reductionist conception of law based on positivism, in legalism and statism, advocating a broad concept of law, recognized as a human phenomenon and social multifaceted. On the

\footnotetext{
${ }^{1}$ Doutor e Mestre em Direito pela UFPR. Professor Adjunto da Universidade Federal do Mato Grosso do Sul. Professor de pós-graduação em Curitiba, Ponta Grossa e Londrina (ABDCOnst, EMAP, IDCC). Professor visitante de outros cursos de pós-graduação (ISAE-FGV, UNICURITIBA). Ex-membro da Societé de Legislation Comparee (Paris) e da Associazione Italiana di Diritto Comparato (Florença). Autor de diversos livros jurídicos. Tradutor de obras jurídicas (livros e artigos). Parecerista de periódicos e eventos científicos (Revista Mineira de Direito - PUC MG, Revista da UNISC, Revista da ABDConst, Revista da Universidade Católica de Brasília - UCB, entre outras). Email: lfsgarbossa@uol.com.br
} 
basis of the thought of Paolo Grossi, proposes a ransom of vision ordenamental of right, in place of conception merely existing compulsory. The study presents a critical approach to purely technological of right, for the sake of a methodological reset that boosts the juridical science, and argues that the expulsion of myths as the legal monism may contribute to a Juridical Science of future succumb ante the strict positivism, the officialdom and the strict technicality.

Key words: Science of Law. Methods. Reductionism.

\section{INTRODUÇÃO E PROPOSTA}

As reflexões acerca do campo do conhecimento jurídico serão desenvolvidas em dois eixos interligados por um problema fundamental, qual seja, a possibilidade de um conhecimento científico do fenômeno jurídico. Para tanto, no âmbito epistemológico levantarse-ão alguns questionamentos sobre a teoria e a metodologia da Ciência do Direito e, paralelamente, no âmbito ontológico, far-se-ão alguns questionamentos sobre o objeto desta Ciência, ou seja, sobre a própria definição de direito.

Parte-se da compreensão preliminar de que é impossível realizar uma discussão adequada sobre as possibilidades de uma Ciência Jurídica sem investigar, de um lado, aquilo que tem sido considerado como tal (e suas limitações) e, de outro lado, qual tem sido a compreensão de seu objeto de estudo.

Parece plausível sustentar a impossibilidade de avançar na compreensão do campo científico-jurídico sem proceder, ao mesmo tempo, a investigações teórico-metodológicas que favoreçam na compreensão do caminho a ser trilhado para a melhor compreensão do objeto e, concomitantemente, a investigações acerca do próprio objeto do conhecimento. ${ }^{2}$

\section{QUESTÕES TEÓRICO-METODOLÓGICAS E A CIÊNCIA DO DIREITO}

Uma indagação inicial fundamental a ser posta em uma discussão mais profunda seria: existiria realmente uma Ciência do Direito?

\footnotetext{
2 Parte-se da premissa da impossibilidade de discutir metodologia sem discutir a teoria que, explícita ou implicitamente, a informa, bem como da impossibilidade de discutir aspectos teórico-metodológicos sem discutir previamente aspectos prementes relativos ao objeto que se pretende conhecer, ainda que de forma provisória.
} 
Sem o intuito de responder a tal indagação, mas sem renunciar a enunciá-la como problematização necessária, problematizar-se-á a temática inicialmente através de algumas considerações críticas sobre o caráter científico do conhecimento jurídico, sem qualquer pretensão de exaustão.

Questionamentos à cientificidade do saber jurídico não constituem algo novo. Como observa Plauto Faraco de Azevedo, a mais célebre contestação a tal caráter científico data de 1847, por ocasião de uma conferência proferida por Julius Hermann Von Kirchmann na Sociedade Jurídica de Berlin (AZEVEDO, 1989, p.32).

Tal questionamento, ao que se percebe, baseia-se ao mesmo tempo em uma problematização do objeto da Jurisprudência e aspectos teóricos ou metodológicos gerais, embora sem uma formalização mais sofisticada e baseada numa noção positivista de ciência hoje reputada ultrapassada (VERNENGO, 1986, p.292).

Kirchmann sustenta a ausência de cientificidade do conhecimento jurídico com base em sua inconstância, sua fugacidade e sua contingência (NOVELLI, p.107). Nas palavras do mesmo, os estudos jurídicos “ na razão de nove décimos, ou mais, ocupam-se das lacunas, dos equívocos e das contradições das leis positivas - do que nelas há de falso, de antiquado ou de arbitrário. Seu objeto é a ignorância, a desídia, a paixão do legislador" (KIRCHMANN apud AZEVEDO, 1989, p.32).

Partindo das limitações que vislumbrava no conhecimento jurídico em função de tais características e embebido do cientificismo típico do século XIX, Kirchmann compara a Jurisprudência com as ciências naturais, apontando para a enorme distância que sustenta existir entre ambos os campos (AZEVEDO, 1989, p.33).

Kirchmann observa que desde Bacon o princípio da subordinação da especulação teórica à observação empírica teria produzido grandes avanços nas ciências naturais, permitindo a formulação de leis gerais e conduzindo a grandes descobertas, coisa que não teria acontecido com o estudo do Direito, que o autor via como estacionário (AZEVEDO, 1989, p.32).

O autor aponta ainda para problemas como o conceptualismo jurídico, afastado da realidade, bem como o "esoterismo" jurídico, na expressão de Antonio Truyol y Serra, consistente em uma hipertrofia construtiva que origina um conhecimento jurídico apartado do senso jurídico popular, sendo apropriado ilegitimamente por juristas profissionais (AZEVEDO, 1989, p.35). 
Segundo Kirchmann, um dos defeitos principais da Jurisprudência de sua época fora, exatamente este afastamento das origens sociais do direito, pelo que o autor preconizava a necessidade de reaproximação do direito à percepção popular do jurídico, que permitiria a realização mais autêntica do direito (AZEVEDO, 1989, p.35).

Sem cair em um "cientismo" ou "cientificismo" ultrapassado e sem a necessidade de se pretender aplicar o estatuto das ciências naturais à Ciência Jurídica, o que seria equivocado, não se pode negar o desconforto em conceber existência de tal ramo do conhecimento científico hoje, posto não se vislumbrar, ainda, uma teoria e uma metodologia consistentes e adequadas que dêem sustentação àquele (NOVELLI, p.109). ${ }^{3}$

Com efeito, é sabido que os cânones do conhecimento jurídico contemporâneo de tradição romano-germânica nascem nas universidades européias e italianas - sobretudo a de Bolonha (DAVID, 2002, p.41) - a partir do século XII (HESPANHA, 2005, p. 141).

A partir dos séculos XII e XIII os cursos jurídicos surgem na Europa resgatando e fazendo uma releitura do direito romano (DAVID, 2002, p.43) com vistas a criar um direito erudito e uniforme e a dar formação a uma miríade de práticos - notários, juízes, advogados fazendo-o a partir de um resgate e de uma releitura do Direito Romano, mesclado a elementos oriundos de outras culturas e tradições jurídicas, com vistas a promover uma uniformidade substitutiva da situação de pluralismo jurídico precedente (HESPANHA, 2005, p. 121). ${ }^{4}$

A base para a construção de um direito uniforme são encontradas nas compilações do imperador Justiniano (DAVID, 2002, p.24). As universidades e o latim proporcionam a formação de uma formação intelectual homogênea dos agentes, com a mesma metodologia ou estilo de raciocinar, calcada notadamente nos grandes manuais de lógica e de retórica (HESPANHA, 2005, p. 122).

Como destacado, além das disciplinas ensinadas não corresponderem ao conhecimento de tipo científico, oriundo de pesquisas metodologicamente orientadas e controladas com vistas à demonstração e experimentação, a orientação dos cursos jurídicos era eminentemente prática.

\footnotetext{
${ }^{3}$ Mariano Novelli, após evidenciar as limitações epistemológicas da crítica de Kirchmann reconhece um valor remanescente da mesma, qual seja, a de que a ciência do direito esteja em constante desenvolvimento, atendendo em medidas cada vez maiores a compreensão da realidade social.

${ }^{4}$ António Manuel Hespanha observa que o "direito comum”, doutrina jurídica dos séculos XV a XVII, ostenta como característica distintiva a unidade, na medida em que unifica as várias fontes do direito (direito justinianeu, direito canônico e direitos locais), estabelece um objeto bem como métodos e estilos de raciocinar comuns à toda a Europa, forjados em um ensino universitário idêntico e vulgarizados pelo latim.
} 
Se aceitarmos provisoriamente um conceito de ciência como um conjunto sistemático de conhecimentos sobre um objeto delimitado, metodologicamente orientado e suscetível de experimentação ou verificação (ao menos em algum grau), observa-se tratar-se de conhecimento voltado precipuamente para a produção de conhecimento, sendo secundária a aplicação prática (MELLO, 2005, pp. 14 e ss.). Já a tecnologia poderia ser compreendida adequadamente como um conjunto de conhecimentos - tenham eles origem científica ou não - aplicáveis na resolução de problemas concretos.

Aceitando-se previamente tais conceitos, ainda que sujeitos a discussões, verifica-se que embora ambos constituam tipos de conhecimento, a ciência estaria voltada a conhecer e verificar o conhecimento, ao passo que a tecnologia estaria preocupada com aplicar o conhecimento, independentemente de sua explicação ou origem científica ou outra.

Assim, parece plausível sustentar que um conjunto sistematizado de conhecimentos poderia ser mais apropriadamente compreendido como tecnologia do que como ciência caso seu objetivo primordial fosse a pacificação social através da aplicação de normas jurídicas (EHRLICH, 1986, p.09).

Nas academias de Direito formaram-se várias disciplinas de caráter dogmático, calcadas na autoridade de escritos de origem romana, e centradas em técnicas de operação concreta do direito com vistas a finalidades práticas, estudando-se especialmente métodos de operação do direito (interpretação, argumentação, retórica, lógica, solução de antinomias) (EHRLICH, 1986, p.14).

Parece-nos plausível afirmar que a principal preocupação era de ordem eminentemente prática, a saber, de um lado, prover a tão necessária uniformização do direito, fragmentada no período feudal; de outro, prover a tão necessária profissionalização dos juristas, com vistas, entre outras coisas, à segurança jurídica. Ademais este fenômeno não parece estar desconectado das mudanças sociais e econômicas e do advento da burguesia e do capitalismo moderno.

Daqui depreende-se desde logo que, se compreendermos provisoriamente a ciência como uma atividade de busca do conhecimento ou da verdade (ou "quase-verdade", na expressão de Newton da Costa), ainda que desprovida de aplicações práticas imediatas, o que se consolidou como "ciência do Direito" a partir das Faculdades de Direito até nossos dias dificilmente poderia ser compreendido em termos de ciência propriamente dita (EHRLICH, 1986, p.14). 
Parece concebível a compreensão segundo a qual a atividade desenvolvida nos cursos de Direito, eminentemente presa à atividade prática dos juristas, como o conhecimento do direito estatal, a elaboração de contratos, a interpretação e aplicação de estatutos, ao processo e assim por diante parece melhor enquadrar-se a um conceito de tecnologia do que de ciência propriamente dita, na medida em que se constituíam em um conjunto de conhecimentos ("científicos" ou empíricos, não importa) voltados eminentemente a aplicações práticas e à solução de problemas práticos (HABA, 1993).

Ao que parece, com o passar do tempo, tais conhecimentos ganharam, em função do prestígio dos Cursos de Direito e de seus membros, o status de "científicos", haja vista a importância e o prestígio do conhecimento assim alcunhado a partir do positivismo, sem significativas alterações quanto àquilo que se compreendia como os conhecimentos que compunham dita "ciência" e tampouco quanto aquilo que se compreendia como sendo seu objeto.

Mesmo as grandes sistematizações do Direito como a feita por Hans Kelsen parecem não ter conseguido vencer o desafio de dotar a "ciência" do Direito de uma metodologia científica. Os instrumentos largamente utilizados, notadamente a lógica, revelaram-se absolutamente inadequados. ${ }^{5}$

Daí algumas críticas, como a realizada pelas escolas do realismo norte-americano e escandinavo, no sentido de que uma ciência jamais poderia ser "normativa", como pretendia Kelsen. ${ }^{6}$

Além disso, o objeto do saber jurídico, depois da derrocada do jusnaturalismo, passa a ser o direito "positivo", estatal, autoritariamente imposto, recusando-se qualquer valor às compreensões mais amplas do fenômeno jurídico e qualquer validade a manifestações extraestatais do Direito, salvo excepcionalmente.

O objeto desta "ciência prática", como alguns denominaram para tentar conferir coerência às inconsistências daquela "ciência" jurídica seria o direito entendido como instrumento de controle e pacificação social (e, posteriormente, de "engenharia" social).

\footnotetext{
${ }^{5}$ Remete-se à crítica de Alf Ross quanto ao particular. Quanto à lógica, basta relembrar a tomada de consciência da impropriedade da utilização da lógica clássica no campo jurídico e a necessidade, quanto aos empreendimentos neste sentido, de lançar-se mão das lógicas não-monotônicas, notadamente as lógicas paraconsistentes.

${ }^{6}$ Vide, por todos, Alf Ross.
} 
Vislumbra-se um objeto reduzido (direito reduzido a Direito estatal, autoritariamente posto, imposto e sancionado pelo Estado) e uma confusão tremenda entre métodos científicos e métodos e técnicas interpretação e aplicação do direito estatal escrito, com vistas à pacificação e controle social, através da resolução de conflitos. ${ }^{7}$

Os primeiros buscam conhecer, os últimos buscam resolver problemas concretos, pelo que consideram-se, aqui, categorias irredutíveis umas às outras. Não é possível, s.m.j., compreender que métodos e técnicas de interpretação (literal, léxica, gramatical, filológica, histórica, sistemática, teleológica, etc.), de aplicação (subsunção lógica, p. ex.); de resolução de conflitos de normas (como os critérios lex superior, lex posterior, lex specialis), de colmatação de lacunas ou integração do direito (analogia) sejam métodos científicos, até porque não buscam a "verdade" (ou quase-verdade) sobre os fenômenos que (não) estudam, mas fundam-se no estabelecimento de critérios que resolvem (bem ou mal) problemas concretos.

Sustenta-se que a despeito das várias correntes que, em maior ou menor medida, buscaram renovar a discussão teórica e metodológica acerca do direito, como, por exemplo, os movimentos da livre investigação científica, do direito livre e as diversas orientações filiadas ao denominado "realismo jurídico", não se obteve êxito em criar um paradigma rival ao paradigma ora dominante no campo jurídico (normativismo positivista) e muito menos em provocar uma séria contestação (na prática cotidiana do cultivo do Direito na maioria das Universidades) das premissas da "ciência" jurídica normativista. ${ }^{8}$

Então, colocando-se sinteticamente o problema, ao que parece não possuímos até o momento uma teoria que dê conta, adequadamente, do campo epistemológico do Direito - eis que o normativismo há muito já demonstrou suas fraquezas, o que ficará ainda mais claro no item sucessivo - e tampouco uma metodologia científica séria, que dê conta de toda a complexidade do objeto de estudo a que nos dedicamos.

\footnotetext{
${ }^{7}$ Posto que em regra o que se aprende nas academias de direito são técnicas de interpretação e aplicação do direito e largas doses de dogmática jurídica. A metodologia da pesquisa científica em ciências sociais ou mesmo direito reduzem-se à disciplina de metodologia da pesquisa científica ou jurídica a qual, infelizmente, por muitas vezes, é reduzida, ainda, à concepção do ensino de normas técnicas. Comparativamente a outras ciências sociais, como a Economia, a Sociologia, a História e a Antropologia, é forçoso concluir pela ausência de uma discussão metodológica mínima no campo jurídico.

${ }^{8}$ Em nosso juízo as correntes que chegaram mais próximas de uma séria contestação e oposição ao formalismo (eis que se opunham ao positivismo jurídico norte-americano do estilo de Langdell) foram as correntes realistas.
} 
E embora não se pretenda, como dito, impor o estatuto epistemológico das ciências naturais $^{9}$ às ciências sociais (gênero do qual uma futura ciência jurídica constituiria uma espécie), tem-se a grave situação de não se possuir uma teoria consistente que dê conta de orientar uma ciência e, ainda, de não se possuir sequer um aparato metodológico adequado à compreensão do objeto.

Deve-se reconhecer, porém, que um número crescente de juristas e cientistas sociais que se ocupam do direito tem, em muitos casos pela percepção dos problemas e limitações da "ciência jurídica", aproximado este ramo do conhecimento de outros afetos às ciências humanas e sociais, como a Antropologia, a Sociologia, a Economia, a Psicologia, a História, a Geografia, a Ciência Política, entre outras. ${ }^{10}$

Tais aproximações têm sido muito valiosas, e produzido bons resultados na superação de alguns vícios que limitavam demasiadamente as perspectivas e os horizontes do estudo do direito.

Nada obstante, apesar de todos os bons frutos e todas as virtualidades de tais aproximações, parece-se estar diante de mera transdisciplinaridade e, raras vezes, interdisciplinaridade. Propugna-se que algo mais radical seria necessário e desejável: a apropriação interna de métodos e técnicas de investigação oriundos de outras ciências para a construção de uma ciência do Direito. ${ }^{11}$

Vale dizer, após uma redefinição (que consideramos necessária) do objeto da Ciência Jurídica (afinal, o que é o direito?), e de acordo com esta redefinição, faz-se necessária a adoção sistemática de métodos e técnicas de investigação apropriadas, como, por exemplo (aqui trata-se de mera especulação), questionários, entrevistas, observação sistemática, observação participante, método diagramático, estatístico, teoria dos jogos, análise combinatória, lógicas não-clássicas, métodos comparativo, genealógico, sincrônico, diacrônico, entre outros.

\footnotetext{
${ }^{9}$ Até porque este também encontra-se em crise paradigmática.

${ }^{10}$ Veja-se, por todos, Boaventura de Sousa Santos, especialmente as obras Um discurso sobre as Ciências e, particularmente, Crítica da razão indolente: contra o desperdício da experiência.

${ }^{11}$ Entende-se aqui que é diferente utilizar aportes da Economia, Sociologia ou História como apoio ou suporte às investigações mas, em seguida, prosseguir com estudos "dogmáticos". Parece ser necessário redefinir metodologicamente a "ciência" do direito, introduzindo à mesma a metodologia e as técnicas de pesquisa e de investigação científica das demais áreas, como feito por outras ciências, como a Economia.
} 
Mas antes de serem utilizados paralela e externamente, de maneira assistemática, tais métodos poderiam ser integrados em torno e uma teoria integradora que desse consistência à sua utilização, para evitar uma miscelânea metodológica de efeitos dúbios.

A guisa de conclusão, de se consignar que não se ignora as diversas modificações do próprio conceito de ciência, operadas pelos avanços na Epistemologia a partir de autores como Hanson, Polanyi, Kuhn, Toulmin, Lakatos e Fayerabend, que relativizaram significativamente as noções acerca de ciência precedentemente em vigor (NOVELLI, p.107).

No entanto, parece plausível afirmar que não se pode aceitar, por isso, que o que se compreende ainda largamente como "ciência" jurídica seja realmente concebido como tal apenas por tradição, e é com preocupação que se vislumbra ainda a ausência de um questionamento e de um debate sistemático e sério quanto à metodologia a ser empregada no âmbito jurídico para viabilizar um conhecimento científico adequado ao objeto, cuja complexidade se evidencia em parte no tópico seguinte.

\subsection{O Objeto Da Ciência Jurídica E Sua Complexidade: O(S) Direito(S)}

Além das questões mais propriamente metodológicas, mas absolutamente conexa a elas, encontra-se a questão da definição do objeto da pretendida Ciência Jurídica.

Há bastante tempo o positivismo, com seu ceticismo metafísico característico, baniu não só as temáticas jusnaturalistas do campo da investigação jurídica, mas igualmente promoveu um reducionismo do direito ao direito positivo, posto ou estatal, vale dizer, o direito criado e estabelecido autoritariamente por algum órgão estatal, seja o legislador nos sistemas romano-germânicos, seja o juiz, no sistema do Common Law.

Dá-se o que alguns historiadores do direito, como Paolo Grossi, denominam "absolutismo da lei", sendo que a lei imposta pela estatalidade passa a ser compreendida como a única fonte do direito.

Ocorreu, assim, artificialmente, uma imensa simplificação do objeto de estudo de uma possível Ciência Jurídica, reduzindo-o ao direito estatal positivo. Com isso, excluiu-se do campo da investigação jurídica propriamente dita toda uma gama de possíveis manifestações extra-estatais do direito. 
Ocorre que, ao que parece, analisando com maior vagar a questão, o direito consistiria em um fenômeno muito mais complexo do que à simples manifestação de normas postas autoritariamente pelo Estado.

Investigações históricas e antropológicas, assim como sociológicas, estão a demonstrar que o direito é fenômeno que preexiste à própria estatalidade e à sua própria verbalização.

Assim, a História do Direito e a Antropologia Jurídica, bem como da Sociologia Jurídica, têm demonstrado que a par da concepção de direito estatal ou positivo, existem outras concepções do fenômeno jurídico que são irredutíveis ao último, sem necessariamente remontarem a algum tipo de jusnaturalismo ou outra concepção metafísica.

Antes da afirmação de uma Antropologia Jurídica como ramo da Antropologia existia uma compreensão difundida entre os antropólogos no sentido de que o direito era uma exclusividade das complexas sociedades modernas, inexistindo em sociedades sem Estado e sem escrita, compreensão esta esposada por ninguém menos do que Radcliffe-Brown, um dos expoentes da antropologia. ${ }^{12}$

Posteriormente, uma completa revisão destes conceitos é promovida por Bronislaw Malinowski, evidenciando a existência de um ordenamento jurídico mesmo entre povos simples, sem centralização do poder (ou seja, sociedades “acéfalas" ou sem Estado).

Os estudos de Malinowski e outros que a ele se sucederam evidenciaram que a despeito da ausência de um poder estatal, de tribunais permanentes ou de juristas profissionais havia em toda sociedade uma concepção de direito. O conceito estrito de direito de RadcliffeBrown cede passo ante a concepção ampla de direito de Bronislaw Malinowski (GRANDE, 1996, p. 468-469).

Diversos estudos passam a demonstrar e a investigar manifestações jurídicas em sociedades simples ou acéfalas, utilizando-se de métodos inovadores para a compreensão do direito naquelas sociedades (GRANDE, 1996, p.469). Assim, conforme Elisabetta Grande

\footnotetext{
Dopo lo studio di Hoebel e Llewellyn la questione se le società prive de scrittura, di corti, di giuristi, di legislatori e di potere centralizzato potessero avere un diritto fu definitivamente risolta in senso positivo e con essa furono accantonati in buona misura anche i tentativi di dare una definizione restrittiva del concetto di regola giuridica e di diritto (GRANDE, 1996, p.470).
}

\footnotetext{
12 Tal compreensão decorre exatamente da concepção reducionista do direito estabelecida pelo positivismo jurídico, segundo a qual onde quer que não se encontrasse o Estado, as leis escritas, os tribunais e os juristas profissionais não haveria direito.
} 
Entre as inovações metodológicas que possibilitaram a pesquisa do direito em sociedades simples encontra posição central o denominado case-method, através do qual se busca superar os problemas da inexistência de um direito escrito e estabelecido por leis emanadas da autoridade política (em alguns casos inexistente) estudando o teor do direito dos povos simples a partir de casos concretos e sua resolução dentro daquela sociedade (GRANDE, 1996, p. 470).

Posteriormente, outras orientações - até mesmo críticas ao case-method - surgiram; no entanto, desde então, ficou afastado o dogma no sentido da exclusividade do fenômeno jurídico relativamente às sociedades complexas, e a questão metodológica passou a ser objeto de sistemática atenção.

Além disso, os desenvolvimentos da Antropologia Jurídica infirmaram as concepções evolucionistas, evidenciando não apenas que o direito não constituía monopólio estatal, deitando antes suas raízes mais profundas na sociedade e em sua cultura, como também o método jurisdicional de solução das controvérsias estava longe de ser o ápice de um processo linear e cumulativo de progresso, evidenciando-se o valor de outras formas de solução de controvérsias (GRANDE, 1996, p. 490 e ss.).

Mais do que isso: a Antropologia Jurídica acabou por demonstrar mesmo que sequer a linguagem escrita é imprescindível para o fenômeno jurídico, verificando-se este mesmo em sociedades nas quais a escrita era desconhecida, as sociedades ágrafas. Como observa Elisabetta Grande, uma das grandes contribuições da Antropologia Jurídica para com o conhecimento do direito é justamente o fato de ter evidenciado que "regole giuridiche $e$ principi generali non sono dunque assenti nella società senza scrittura e senza stato" (GRANDE, 1996, p. 479), o que tem amplo impacto tanto na redução do direito ao direito estatal quanto na sua redução ao direito escrito.

Alguns antropólogos têm dedicado mesmo a atenção a um direito mudo, que seria não apenas não escrito, mas também sequer verbalizado, o que tem demonstrado as potencialidades de uma análise mais profunda do fenômeno jurídico para sua compreensão, e a extrema complexidade do direito. ${ }^{13}$

\footnotetext{
13 Rodolfo Sacco, professor da Universidade de Turim e estudioso da Antropologia Jurídica e do Direito Comparado, tem estudado e desenvolvido a teoria dos formantes jurídicos, teoria de cunho estruturalista através da qual busca-se evidenciar, pelo método comparativo, a dissociação dos formantes legal, jurisprudencial e doutrinário (entre outros) e a existência de regras ocultas e não-verbalizadas em qualquer ordenamento jurídico (inclusive nos ordenamentos das sociedades complexas modernas ocidentais).
} 
Assim a Antropologia Jurídica e seus avanços têm enorme impacto sobre a concepção de direito e sobre as noções positivistas, normativistas e estatalistas do mesmo, na medida em que evidencia a transcendência do fenômeno jurídico relativamente à esfera do estatal e, ainda, à própria redução a escrito ou - até mesmo - à verbalização (GRANDE, 1996, p. 489).

Historiadores do Direito têm levantado, igualmente, evidências significativas que apontam para a complexidade do direito e, ao mesmo tempo, para as insuficiências da concepção positivista-normativista de direito.

É o caso de Paolo Grossi, o qual, em sua obra $O$ direito entre poder e ordenamento evidencia a distância que medeia as concepções potestativa e ordenamental do Direito, com base em Santi Romano.

Com efeito, Grossi demonstra que anteriormente à concepção contemporânea de direito como ordem potestativa imposta pelo Estado, pelo poder centralizado, vigorava outra, mais ampla e compreensiva.

Tal concepção compreendia o Direito como um fenômeno social, imanente à própria sociedade, interpretando atos legislativos ou judiciais muito mais em um sentido de declarar o direito vigente do que estabelecê-lo. ${ }^{14}$ Neste sentido, o magistério de Paolo Grossi parece ser exemplar, ao evidenciar que, durante a Idade Média, diante da ausência de um poder político central foi possível ao direito recuperar toda sua onticidade ordenante:

\begin{abstract}
O direito, aqui, é sobretudo, ordo, ordem, não assegurada pela coerção de uma ordem de polícia, mas em vigor nos estratos mais profundos da sociedade; uma ordem que espera somente para ser lida, conhecida, manifestada, porque já está escrita com características indeléveis. (...) O resultado é claro, e é um grande momento: o direito nasce de baixo, existe uma prevalente dimensão objetiva, permanecendo no Príncipe o papel respeitável, mas secundário, de manifestador público das regras através dos trâmites da promulgação (GROSSI, 2000, p.96-97).
\end{abstract}

Nesta concepção, o direito é profundamente e inerentemente social em sua essência e existência, tendo natureza predominantemente consuetudinária - e não estatal - e sendo concebido como declarado pelas autoridades, e não por elas criado, sendo interpretado e não criado pelos juristas (GROSSI, 2000, p.97-98).

\footnotetext{
${ }^{14}$ Concepção muito similar está muito presente no Common Law, segundo o qual as decisões judiciais
} efetivamente não criam o direito aplicável, antes revelam-no a partir do Common Law. 
Como observa Grossi, este é um direito de compleição totalmente diversa daquela do direito estatal contemporâneo, conforme é por nós compreendido. Tal concepção ordenamental de direito traduz-se em um direito que

(...) pode registrar e registra a complexidade do social. Não a oprime, não a reduz, como acontece debaixo daquela capa de chumbo que chamamos Estado, poder político voraz e totalitário, que será a presença que caracteriza a modernidade européia continental: simplesmente a registra com a máxima felicidade (GROSSI, 2000, p. 98).

Posteriormente, com o advento da modernidade e a centralização do poder nas mãos do soberano do Estado moderno é que se verifica o advento de uma concepção não mais ordenamental, mas potestativa do direito, reduzindo-o a instrumento de governo e a expressão da vontade do soberano:

\footnotetext{
O direito se resume e se conecta sempre mais ao poder; aliás, o expressa. O direito se subjetiva, ou seja, se encarna sempre mais na vontade do Soberano, uma vontade muitas vezes arbitrária e que geralmente coincide, como adverte com desenvoltura Jean Bodin no final do Século XVI, com a sua vontade, ou seja, com a mais indiscutível das dimensões do sujeito. A lei perde aquele duplo caráter de ordenamento e de ato racional (que já pareciam insensatas limitações ao poder do Soberano), é ato de vontade, é ato de império, é comando. O direito se vê reduzido ao grau de instrumento de controle social, se tornando um artifício, uma criação do titular da soberania (GROSSI, 2000, p.100).
}

Devem ser recordados, ainda, necessariamente, os aportes da sociologia do Direito à compreensão deste fenômeno, como, por exemplo, a partir da obra de Eugen Ehrlich, precursor e figura principal da orientação denominada Direito Vivo (Lebensrecht), que resgatava exatamente tal caráter pré-estatal e extra-estatal do Direito.

Ehrlich em sua obra principal (Grundlegung der Soziologie des Rechts ou Fundamentos de Sociologia do Direito) evidencia a raiz social e extra-estatal do direito (TREVES, 2004, p.119), deduzindo daí as limitações dos estudos jurídicos de então e a necessidade de fundação, a partir do caráter social do direito, de uma verdadeira ciência jurídica (TREVES, 2004, p.120).

Nas palavras de Renato Treves, a tese de Ehrlich sobre a ciência jurídica assenta-se na premissa de que sua tarefa seria 
conhecer e descrever o concreto e não o abstrato, os fatos, não as palavras e, portanto, tem por objeto não somente o direito 'válido para os tribunais e órgãos de autoridade', mas também, e especialmente, o direito vivente que, 'não formulado em proporções jurídicas', regula toda a vida social (TREVES, 2004, p.120).

Ou seja, Ehrlich é outro autor que escapa à visão estatalista e reducionista do jurídico, percebendo as dimensões de amplitude do objeto e, conjuntamente, a insuficiência do ferramental dos estudos jurídicos para a adequada apreensão da realidade complexa e rica do fenômeno jurídico.

Ehrlich sustenta que a maior parte do direito origina-se imediatamente da sociedade, sendo a regulação jurídica formal posterior, pelo que a norma jurídica seria condicionada pela sociedade, aplicável se e na medida em que observe seus pressupostos sociais (TREVES, 2004, p.121). O autor distingue entre normas de organização, regentes da vida social propriamente ditas, de normas de decisão, que dirigem-se sobretudo para os juízes e cujo papel não é o de estruturar a sociedade, mas de proteger sua estrutura e resolver os conflitos (TREVES, 2004, p.122).

De se observar com Treves que dez anos antes da obra fundamental de Hermann Kantorowicz, propugnando pela livre investigação do direito, em 1903 Ehrlich já sustentava a livre investigação do direito e uma ciência do direito que não o identificasse com a estatalidade e que se desviasse das falácias da completude do ordenamento jurídico estatal (TREVES, 2004, p.123).

\section{CONCLUSÃO}

Percebe-se desta brevíssima incursão nos campos da Antropologia Jurídica, da História do Direito e da Sociologia Jurídica que o objeto de uma Ciência Jurídica não é obvio, não sendo evidente que se reduza ao conjunto de normas produzidas pelo Estado.

Naturalmente, os avanços induzidos na compreensão do fenômeno jurídico no campo de outras ciências devem ter repercussão no campo do estudo jurídico (a menos que se pretenda permanecer dogmaticamente vinculado a uma concepção estatalista e normativista de direito), e que o próprio objeto de uma Ciência Jurídica deve ser estabelecido.

Sustenta-se, neste ponto, que seria imprescindível o abandono de uma concepção legalista e estatalista do direito (direito como direito positivo), por excessivamente 
reducionista e insatisfatória, em prol de uma concepção ampla de direito (direito como fenômeno humano e social multifacetário).

Assim o objeto das investigações jurídicas retomaria sua complexidade, permitindo um estudo verdadeiramente científico, e não meramente técnico ou tecnológico, com vistas à aplicação prática.

Naturalmente, tal estudo voltar-se-ia a ser descritivo do direito (haja vista a tarefa primordial da ciência em compreender e explicar os fenômenos que constituem seu objeto), e jamais prescritivo como defendia Kelsen.

Naturalmente o conjunto de conhecimentos produzidos a partir da atividade de pesquisa científica sobre o jurídico poderia vir a ter aplicações práticas posteriores, mas este não deveria ser seu intuito primordial.

Seria imperativo separar-se o âmbito mais estritamente tecnológico do direito (seu estudo com vistas à sua aplicação prática) de seu âmbito mais estritamente científico (seu estudo sistemático, metodologicamente controlado e em busca de um saber fundado).

Do quanto foi visto neste segundo item a partir da Sociologia, da História e da Antropologia, resta claro que o próprio objeto da Ciência Jurídica parece reclamar uma redefinição e readequação.

Com efeito, não pode o saber jurídico permanecer isolado dos novos conhecimentos acerca de seu objeto trazidos por outras áreas do conhecimento, pelas demais ciências humanas e sociais.

A revelação pela Sociologia, Antropologia e História do Direito da irredutibilidade do fenômeno jurídico à estatalidade e à linguagem escrita (ou mesmo a qualquer linguagem) evidenciam as profundas raízes sociais, culturais e quiçá psicossociais do direito.

A visão ordenamental do direito, trazida, entre outros, por Paolo Grossi, evidencia outro aspecto fundamental deste direito, qual seja, sua irredutibilidade a um conceito meramente "potestativo", evidenciando que aquelas raízes sociais e culturais redundam em sua dimensão ordenamental que não deve ser descurada. ${ }^{15}$

\footnotetext{
15 Esta visão é de uma intrigante proximidade com a concepção de Eugen Ehrlich. Como observa Treves, "segundo Ehrlich, o direito é por sua natureza, como vimos, ordenamento interno das relações sociais, ou melhor, organização dos grupos sociais, isto é, um complexo de regras que determina a posição e a função dos membros individuais do grupo e, mais precisamente, as condições de coordenação e de subordinação dos mesmos e dos papéis específicos de cada um no âmbito do grupo.” TREVES, R. op. cit. p. 121.
} 
Naturalmente a redefinição do objeto exerce notável impacto sobre os aspectos metodológicos, os quais deveriam ser construídos a partir das complexidades e peculiaridades deste objeto, a partir de métodos experimentados pelas demais ciências, sobretudo humanas e sociais.

Tal redefinição, evidenciando a imensa e insuspeita complexidade do objeto de estudo, oculta durante tanto tempo sob as crenças difundidas pelo positivismo jurídico, terá impactos teóricos, analíticos e metodológicos que exigirão um enorme esforço de sistematização e de reorganização dos métodos e técnicas de estudo e pesquisa do direito, de modo a favorecer imensamente o advento de uma verdadeira Ciência Jurídica, que não mais se reduza a aspectos fugazes e circunstanciais do direito, como denunciava Kirchmann ainda no século XIX, mas que lance luzes sobre seus aspectos mais profundos e importantes.

Em suma, conforme evidencia Grossi, o afastamento dos mitos da lei, do monismo jurídico e outros correlatos revelam outro direito e, portanto, outro objeto para a Ciência Jurídica, em toda sua complexidade.

\section{REFERÊNCIAS}

AZEVEDO, Plauto Faraco de. Crítica à Dogmática e Hermenêutica Jurídica. Porto Alegre: Sergio Antonio Fabris Editor, 1989.

DAVID, René. Os grandes sistemas do Direito Contemporâneo. Trad. Hermínio A. Carvalho, São Paulo: Martins Fontes, 2002.

EHRLICH, Eugen. Fundamentos da Sociologia do Direito. Trad. René E. Gertz. Brasília : Editora da UnB, 1986.

GRANDE, Elisabetta. L'apporto dell'Antropologia alla conoscenza del diritto. In: Rivista Critica del Diritto Privato, anno XIV, n. 3, set. 1996, Napoli: Jovene Editore.

GROSSI, Paolo. Direito entre poder e ordenamento. Trad. Arno Dal Ri Junior. Rio de Janeiro: Del Rey, 2000.

HABA, Henrique P. Kirchmann sabía menos... pero vio mejor! Vigencia de un antiguo diagnostico, más algumas observaciones (que no son simpáticas) sobre la actual Teoría del Derecho. Doxa: Cuadernos de Filosofía del Derecho, n. 14, Alicante, 1993, pp. 269-317.

HESPANHA, António Manuel. Cultura Jurídica Européia: síntese de um milênio. Florianópolis: Boiteux, 2005.

MELLO, Luiz Gonzaga de. Antropologia Cultural: iniciação, teoria e temas. 12. ed. Petrópolis: Vozes, 2005. 
NOVELLI, Mariano H. Las ideas de Kirchmann acerca de la Ciencia Juridica: consideraciones sobre epistemología y derecho. Revista del Centro de Investigaciones de Filosofía Jurídica y Filosofía Social, pp. 103-109.

SANTOS, Boaventura de Sousa. Um discurso sobre as ciências. 7. ed. São Paulo: Cortez, 2010.

SACCO, Rodolfo. Antropologia giuridica. Bologna: Il Mulino, 2007.

TREVES, Renato. Sociologia do Direito: origens, pesquisas e problemas. Trad. Marcelo Branchini. 3. ed. Barueri: Manole, 2004.

VERNENGO, Roberto J., "Ciencia jurídica o técnica política: ¿Es posible una ciencia del derecho?", en "Doxa. Cuadernos de Filosofía del Derecho", № 3, Alicante, 1986, pág. 292 e ss. 